\title{
Pliocene and Pleistocene diversification and multiple refugia in a Eurasian shrew (Crocidura suaveolens group)
}

\author{
Sylvain Dubey ${ }^{\mathrm{a}, *}$, Mikhail Zaitsev ${ }^{\mathrm{b}}$, Jean-François Cosson ${ }^{\mathrm{c}}$, Ablimit Abdukadier ${ }^{\mathrm{d}}$, \\ Peter Vogel ${ }^{\text {a }}$ \\ a Department of Ecology and Evolution, University of Lausanne, CH-1015 Lausanne, Switzerland \\ ${ }^{\mathrm{b}}$ Zoological Institute, Russian Academy of Sciences, 199034 Saint Petersburg, Russia \\ ${ }^{\mathrm{c}}$ Centre de Biologie et de Gestion des Populations, UMR 1062, Campus International de Baillarguet, CS 30016, 34988 Montferrier/Lez cedex, France \\ ${ }^{\mathrm{d}}$ Xinjiang Institute of Ecology and Geography, Chinese Academy of Sciences, Urumqi, Xinjiang 830011, China
}

Received 16 February 2005; revised 17 October 2005; accepted 9 November 2005

\begin{abstract}
We sequenced 998 base pairs (bp) of mitochondrial DNA cytochrome $b$ and $799 \mathrm{bp}$ of nuclear gene BRCA1 in the Lesser white-toothed shrew (Crocidura suaveolens group) over its geographic range from Portugal to Japan. The aims of the study were to identify the main clades within the group and respective refugia resulting from Pleistocene glaciations. Analyses revealed the Asian lesser white-toothed shrew (C. shantungensis) as the basal clade, followed by a major branch of C. suaveolens, subdivided sensu stricto into six clades, which split-up in the Upper Pliocene and Lower Pleistocene (1.9-0.9 Myr). The largest clade, occurring over a huge range from east Europe to Mongolia, shows evidence of population expansion after a bottleneck. West European clades originated from Iberian and Italo-Balkanic refugia. In the Near East, three clades evolved in an apparent hotspot of refugia (west Turkey, south-west and south-east of the Caucasus). Most clades include specimens of different morphotypes and the validity of many taxa in the C. suaveolens group has to be re-evaluated.
\end{abstract}

(C) 2005 Elsevier Inc. All rights reserved.

Keywords: Crocidura suaveolens; Cytochrome b gene; BRCA1 gene; Phylogeography; Colonisation routes; Glacial refugia; Eurasia

\section{Introduction}

It is now generally accepted that Quaternary climatic fluctuations profoundly shaped the genetic diversity of terrestrial biota throughout the Holarctic (Hewitt, 2000). Although different species may have had different refugia, colonisation routes (depending on migration abilities), resilience to environmental change, and stochastic events in their histories, such as local extinction (Hewitt, 2003; Michaux et al., 2005), accumulated data reveal a general picture in Europe involving southern refugia and northward colonisation routes. Locally, mountains and seas acted as significant barriers, isolating populations in different glacial

\footnotetext{
* Corresponding author. Fax: +41216924165.

E-mail address: sylvain.dubey@unil.ch (S. Dubey).
}

refugia and constraining post-glacial migration routes (Hewitt, 1999; Taberlet et al., 1998). Temperate species, which presently occupy central and northern Europe, mainly derive from Mediterranean refugium populations that underwent range expansion in the late glacial and early post-glacial periods (Hewitt, 1996), with a western form deriving from an Iberian refugium and an eastern form from the Italo-Balkanic refugium (Dumolin-Lapegue et al., 1997; Ferris et al., 1993, 1998; Santucci et al., 1998; Thorpe, 1984). Several authors, however, suggest an additional mode of colonisation of central and northern Europe by non-Mediterranean populations, coming from one or more eastern refugia: Caucasus, southern Ural, central Europe, and western Asia (Bilton et al., 1998; Cooper et al., 1995; Michaux et al., 2004; Nesbo et al., 1999; Palme and Vendramin, 2002; Seddon et al., 2002). A few other species (Brunhoff et al., 2003; Taberlet et al., 1998) exhibit mixed 
patterns, where northern Europe has been colonised both from Mediterranean and non-Mediterranean refugia.

Notwithstanding some holartic species (Brunhoff et al., 2003) and scant data for temperate species (Ohdachi et al., 2001; Yasuda et al., in press), there are no well-documented phylogeographies encompassing the whole Palaearctic, in spite of the fact that such data may highlight the interrelationships between the Quaternary histories of Asian and European biota and improve our general knowledge of Quaternary refugia in central and eastern Asia. Moreover, such information is relevant for understanding and conserving the current biological diversity in that part of the world. This paper supplies such data by analysing numerous specimens of shrews of the Crocidura suaveolens group with a large distribution throughout the temperate Palaearctic, from Spain to China and Japan (Corbet, 1978; Hutterer, 1981). Within this large area, populations exhibit different morphotypes, which have been interpreted as different species (see Section 2.1 for more details) or have even been assigned as subspecies of other species, e.g., of the Greater white-toothed shrew (C. russula). The common characteristic of all these populations is, however, a similar karyotype with a constant number of chromosomes $(2 N=40, N F=50)$. For this reason, and based on isoenzyme variations, Catzeflis et al. (1985) included all European populations within the same species. Initially, mitochondrial DNA data (Vogel et al., 2003) confirmed this view, showing that the morphologically distinct taxon Crocidura gueldenstaedtii is actually situated within the C. suaveolens clades from southern and western Europe. Other authors still continue to defend the classic view with the distinction of several species based on geographic morphological variation, but also on molecular data (Bannikova et al., 1993, 2005). Several molecular studies confirm the existence of $C$. sibirica from central Asia (Han et al., 2002; Motokawa et al., 2000) and C. shantungensis from east China, Korea, Cheju, and Tsushima Island, which are distinct from a central European sample of $C$. suaveolens (Ohdachi et al., 2004).

The taxonomic assignment of the sampled populations was done according to Zaitsev (1993), and completed by more recent morphological interpretations (Jiang and Hoffmann, 2001; Motokawa et al., 2000). The phylogeographic structure within the $C$. suaveolens group was first characterised, based on the mtDNA cytochrome $b$ gene (cyt-b), which permits, according to Bradley and Baker (2001), good resolution of the intra and peri-specific levels. The congruence between genetic data and classical morphological interpretations was then examined. Considering that the mitochondrial genome of a taxon can introgress into another closely related taxon (Arntzen and Wallis, 1991; Ruedi et al., 1997; Tegelstrom, 1987), a fragment of the nuclear gene Breast Cancer Susceptibility 1 (BRCA1) was analysed in certain samples. Using such data from both mitochondrial and nuclear genomes, and considering the molecular clock, the colonisation and differentiation of the populations through time and space was reconstructed.

\section{Materials and methods}

\subsection{Origin of the material}

Shrews were collected throughout a large part of Eurasia (Fig. 1 and Table 1). The set of samples included material from the following collections: St. Petersburg (ZISP), Russia; Montpellier (JFC), France; Prague (DZCU), Czech Republic; Lausanne (IZEA), Switzerland. Some sequences were taken from Vogel et al. (2003) and Ohdachi et al. (2004) (Table 1).

For clarification, the following nomenclature was employed in our study:

- C. suaveolens Pallas, 1811 (type locality near Sevastopol, Ukraine), from Portugal to East Asia (Zaitsev, 1993).

- C. shantungensis Miller, 1901; from East China, Korea, Cheju and Tsushima Island (Jiang and Hoffmann, 2001).

- C. sibirica Dukelski, 1930; (type locality Minusinsk, Russia) limited to Siberia and China (Corbet, 1978; Jiang and Hoffmann, 2001; Yudin, 1989).

- C. caspica Thomas, 1907; from south of the Caspian Sea (Zaitsev, 1993; Tembotova, 1999).

- C. gueldenstaedtii Pallas, 1811, with the type locality of Dusheti, Georgia (Grafodatsky et al., 1988; Tembotova, 1999; Zaitsev, 1993).

- C. (russula) monacha Thomas, 1906; from central and east Turkey, and to which were also assigned shrews from Lebanon and Israel (Atallah, 1977).

\subsection{DNA extraction and amplification}

Most of the IZEA samples were first frozen in the field in liquid nitrogen, then kept for several years at $-70^{\circ} \mathrm{C}$, and finally stored in ethanol until DNA extraction. Those of the other collections were directly stored in ethanol. DNA extraction was carried out using the QIA Amp DNA Mini Kit (Qiagen). Double-stranded DNA amplifications of cytochrome $b$ gene $(c y t-b)$ were performed with different combinations of primer pairs L14841/C4, C8/C4, C1/C2, C6/C7, C3/H15915, C5/H15915, and L14841/H15915 (see Table 2 and Irwin et al., 1991). Amplification of the BRCA1 nuclear gene was performed using the primer pairs $\mathrm{B} 1 \mathrm{f} / \mathrm{B} 1 \mathrm{r}$, $\mathrm{Bf} 2 / \mathrm{Br}, \mathrm{Bf} / \mathrm{Br} 2, \mathrm{Bf} / \mathrm{Br} 3, \mathrm{Bf} 3 / \mathrm{Br} 4, \mathrm{Bf} 4 / \mathrm{B} 1 \mathrm{r}, \mathrm{B} 1 \mathrm{f} / \mathrm{Bdr}, \mathrm{Bfa} /$ Br11, Bf11/ Br12, Bf12/ Br13, Bf13/ Br14, Bf14/ Br15, Bf15/ $\mathrm{Br} 16, \mathrm{Bf16} / \mathrm{Br} 17$, and Bf17/ Br18 (Table 2). Amplification conditions for the $c y t-b$ consisted of 35 thermal cycles of 30 s denaturation $\left(60 \mathrm{~s}\right.$ for the set L14841/H15915) at $94^{\circ} \mathrm{C}$, $45 \mathrm{~s}$ annealing $(60 \mathrm{~s}, \mathrm{~L} 14841 / \mathrm{H} 15915)$ at $50^{\circ} \mathrm{C}$ and $60 \mathrm{~s}$ $(120 \mathrm{~s}, \mathrm{~L} 14841 / \mathrm{H} 15915)$ extension at $72{ }^{\circ} \mathrm{C}$. Amplification conditions for the BRCA1 locus consisted of 40 cycles of $45 \mathrm{~s}$ denaturation $\left(60 \mathrm{~s}\right.$, BRCA1f/BRCA1r) at $94^{\circ} \mathrm{C}, 45 \mathrm{~s}$ annealing $(60 \mathrm{~s}, \mathrm{BRCA} 1 \mathrm{f} / \mathrm{BRCA} 1 \mathrm{r})$ at $50^{\circ} \mathrm{C}$ and $90 \mathrm{~s}$ extension $(120 \mathrm{~s}, \mathrm{BRCA} 1 \mathrm{f} / \mathrm{BRCA} 1 \mathrm{r})$ at $72^{\circ} \mathrm{C}$.

PCR products were then electrophoresed on a $1 \%$ agarose gel, visualised with ethidium bromide staining to verify 


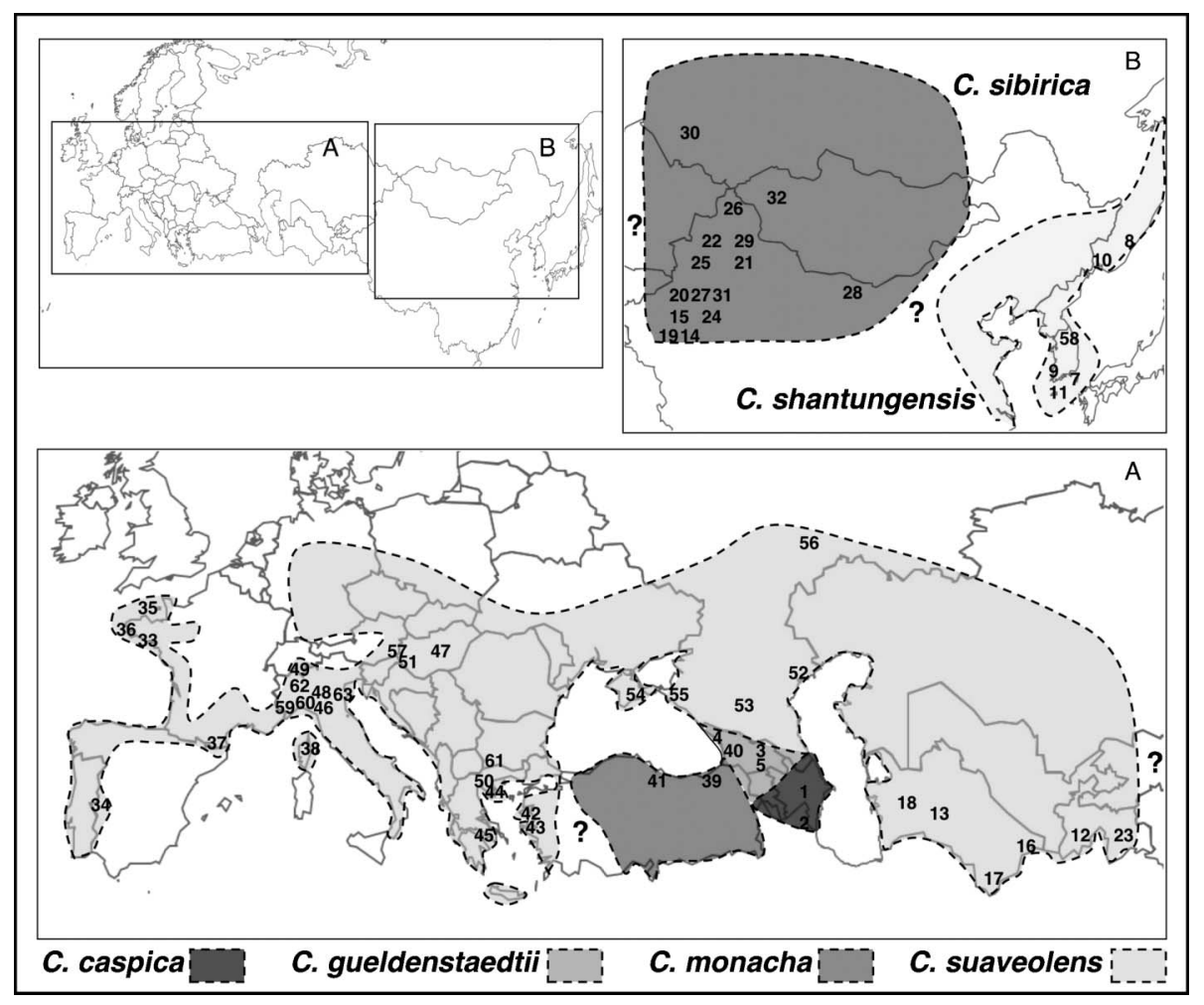

Fig. 1. Locations of samples (A: in western Eurasia, and B: in eastern Eurasia), and currently known repartition of different morphospecies.

PCR quality, and purified by centrifugal dialysis using the QIAquick PCR Purification Kit (Qiagen), according to manufacturer's instructions.

Cycle sequencing was performed in $10 \mu \mathrm{l}$ total volume containing $1-3 \mu \mathrm{l}$ of amplified DNA, $1 \mu \mathrm{l}$ of $10 \mu \mathrm{M}$ primer, $4 \mu \mathrm{l}$ ABI PRISM Dye Terminator 1 (Perkin-Elmer). Sequence reactions were visualised on an ABI 3100 genetic analyser (Applied Biosystems).

\subsection{Phylogenetic methods}

Nucleotide sequences of $c y t-b$ and BRCA1 genes were edited with Sequence Navigator (Parker, 1997) and aligned by eye. Three methods of phylogenetic analyses were carried out for the two genes, using PAUP*version 4.0b8 PPC (Swofford, 1998). Tests were conducted on the total fragments ( $998 \mathrm{bp}$ for $c y t-b, 799 \mathrm{bp}$ for BRCA1), all codon positions were used, and trees were rooted using sequences of $C$. nigripes (DQ059024 for $c y t-b$, and DQ059022 for BRCA1) and C. brunnea (DQ059025 for $c y t-b$, and DQ059021 for BRCA1). A Neighbour Joining (NJ) tree was constructed using Kimura two-parameter genetic distances (K2P; Kimura, 1980). The Parsimony analyses (MP) were performed using the following options: heuristic search, stepwise-addition of sequences, 10 replicates of random addition of taxa, and TBR branch swapping (Swofford, 1998), all codon positions were equally weighted, and as we observed a deletion of three base pairs in some individuals for BRCA1, we treated it as a fifth state. For ML analyses, likelihood ratio tests, implemented with the computer program Modeltest 3.06, were first used to choose the substitution model that best fitted the data, according to the protocol of Posada and Crandall (1998). For $c y t-b$, the $\mathrm{TVM}+\mathrm{G}$ model was selected with base frequencies $(\mathrm{A}=0.2954, \mathrm{C}=0.2710$, $\mathrm{G}=0.1177, \mathrm{~T}=0.3159$ ) estimated from the data, an unequal distribution of rates at variable sites $(\alpha=0.2193)$ and five different substitution types (rate $[\mathrm{A}-\mathrm{C}]=0.3102$, rate $[\mathrm{A}-\mathrm{G}]=[\mathrm{C}-\mathrm{T}]=11.4897$, rate $[\mathrm{A}-\mathrm{T}]=0.8589$, rate $[\mathrm{C}-\mathrm{G}]=0.4558$, rate $[\mathrm{G}-\mathrm{T}]=1.0000$ ). For $\mathrm{BRCA} 1$, the $\mathrm{K} 81$ uf model was selected with a proportion of invariable sites (0), and base frequencies $(\mathrm{A}=0.3828, \mathrm{C}=0.1724$, $\mathrm{G}=0.2070$, and $\mathrm{T}=0.2092$ ) estimated from the data. Maximum likelihood analyses were then performed, assuming this model, using the heuristic search option with a stepwise-addition of sequences. NJ, MP, and ML results were compared for congruence of tree topologies. Bootstrap support values were obtained with 1000 pseudoreplicates for MP, NJ, and ML (for BRCA1) analysis, and 10 random replicates of stepwise-addition sequences. Then, for $c y t-b$, Bayesian analyses were conducted using MrBayes version 3.0 b4 (Huelsenbeck et al., 2001), which performs Metropolis-coupled Markov chain Monte Carlo analysis. A GTR model was used, with an among-site rate variation following a gamma distribution. The Markov chain was run for 1,000,000 generations and sampled once every 100 generations; burning was set at 100,000 generations. To assure convergence in the Bayesian analyses, two independent runs were performed and compared. 


\section{ARTICLE IN PRESS}

Table 1

Species sequenced and used in the present study, geographic origin of samples, identification codes ( $*=$ type locality), location on map (Fig. 1), accession number of $c y t-b$ sequences, and BRCA1 alleles of analysed samples

\begin{tabular}{|c|c|c|c|c|c|c|}
\hline Species & Sample location & Collection codes & $\begin{array}{l}\text { Identification } \\
\text { codes }\end{array}$ & $\begin{array}{l}\text { Number on } \\
\text { the map }\end{array}$ & $\begin{array}{l}\text { Accession number } \\
(\text { cyt-b) }\end{array}$ & $\begin{array}{l}\text { BRCA1 } \\
\text { allele(s) }\end{array}$ \\
\hline C. caspica & Azerbaijan & IZEA 7793 & $\mathrm{AZ1}$ & 1 & AY843487 & A12 \\
\hline C. caspica & Gilan, IR & DZCU IRA87 & IR 1 & 2 & DQ059023 & A12 \\
\hline C. gueldenstaedtii & Sukhumi, GE & IZEA 2854 & GE2 & 4 & AY843496 & \\
\hline C. gueldenstaedtii & Dusheti, GE & IZEA $2687^{*}$ & GE3 & 3 & AY843497 & \\
\hline C. gueldenstaedtii & Shulaveri, GE & ZISP N & GE4 & 5 & AY843500 & A13 \\
\hline C. monacha & Cakalli, TR & IZEA 6014 & TR3 & 41 & AY843502 & A13 \\
\hline C. shantungensis & Tsushima island, JP & IZEA 7510 & $\mathrm{JP} 2$ & 7 & AY843447 & A11 \\
\hline C. shantungensis & Putjatin island, RU & GenBank & RU2 & 8 & AB077080 & \\
\hline C. shantungensis & Kyungju, KR & GenBank & KR1 & 9 & AB077079 & \\
\hline C. shantungensis & Popov Island, RU & GenBank & RU3 & 10 & AB077082 & \\
\hline C. shantungensis & Cheju island, KR & GenBank & KR2 & 11 & AB077077 & \\
\hline C. shantungensis & Popov Island, RU & GenBank & RU5 & 10 & AB077278 & \\
\hline C. suaveolens & Pengikend, TJ & ISP T-77221 & $\mathrm{TJ} 1$ & 12 & AY843478 & \\
\hline C. suaveolens & Firusa, TM & ZISP T-73760 & TM1 & 13 & AY843481 & \\
\hline C. sibirica & Qiemo, CN & IZEA 7504 & CN1 & 14 & AY843470 & \\
\hline C. sibirica & Minfeng, $\mathrm{CN}$ & IZEA 7497 & $\mathrm{CN} 2$ & 15 & AY843468 & \\
\hline C. suaveolens & Kerki, TM & ZISP T-73755 & TM2 & 16 & AY843480 & \\
\hline C. suaveolens & Badchiz, TM & ZISP T-73756 & TM3 & 17 & AY843479 & \\
\hline C. suaveolens & $\mathrm{TM}$ & IZEA 3199 & TM4 & 18 & AY843466 & \\
\hline C. sibirica & Hotan, $\mathrm{CN}$ & IZEA 7491 & $\mathrm{CN} 3$ & 19 & AY843471 & \\
\hline C. sibirica & Aksu Tomor Peak, CN & IZEA 7484 & CN4 & 20 & AY843463 & \\
\hline C. sibirica & Turpan, CN & IZEA 7508 & CN5 & 21 & AY843465 & $\mathrm{A} 1 / \mathrm{A} 2$ \\
\hline C. sibirica & Fukang station, $\mathrm{CN}$ & IZEA 7431 & CN6 & 22 & AY843473 & \\
\hline C. suaveolens & Ikanderkul, TJ & ZISP T-77220 & $\mathrm{TJ} 2$ & 23 & AY843482 & \\
\hline C. sibirica & Novosibirsk, RU & GenBank & RU6 & 30 & AB077279 & \\
\hline C. sibirica & Korla, CN & GenBank & $\mathrm{CN} 15$ & 31 & AB077085 & \\
\hline C. sibirica & Sharg vil. MN & GenBank & MN1 & 32 & AB077088 & \\
\hline C. sibirica & Mosuowan, $\mathrm{CN}$ & GenBank & CN16 & 29 & AB077087 & \\
\hline C. sibirica & Novosibirsk, RU & Coll. Panov N58572 & RU7 & 30 & AY843485 & $\mathrm{A} 1$ \\
\hline C. sibirica & Novosibirsk, RU & Coll. Graphodatsky & RU8 & 30 & AY843486 & $\mathrm{A} 1 / \mathrm{A} 2$ \\
\hline C. sibirica & Novosibirsk, RU & Coll. Bannikova & RU9 & 30 & AY843484 & $\mathrm{A} 1 / \mathrm{A} 2$ \\
\hline C. sibirica & Novosibirsk, RU & GenBank & RU10 & 30 & AB077089 & \\
\hline C. suaveolens & Hoedic, FR & JFC Hoedic & FR1 & 33 & AY843490 & \\
\hline C. suaveolens & Candelario, ES & IZEA 5927 & ES1 & 34 & AY843492 & \\
\hline C. suaveolens & Sark, GB & JFC Sark & GB1 & 35 & AY843489 & \\
\hline C. suaveolens & Triélen, FR & JFC Triélen & FR2 & 36 & AY850035 & \\
\hline C. suaveolens & Figuerasse, ES & IZEA 3191 & ES2 & 37 & AY843491 & A10 \\
\hline C. suaveolens & Bonifacio, Corse, FR & IZEA CO2 & FR3 & 38 & AY843501 & \\
\hline C. suaveolens & Lesvos, GR & IZEA 3930 & GR1 & 42 & AY843460 & A8 \\
\hline C. suaveolens & Vukarikisilka,TR & IZEA 6005 & TR4 & 43 & AY843461 & A7 \\
\hline C. suaveolens & Epanomi Thessalonichi, GR & IZEA 3916 & GR2 & 44 & AY843448 & A4 \\
\hline C. suaveolens & Athina, GR & IZEA 1354 & GR3 & 45 & AY843455 & \\
\hline C. suaveolens & Fivizano, IT & IZEA 489 & IT1 & 46 & AY843450 & \\
\hline C. suaveolens & Hungary & JFC H15 & HU1 & 47 & AY843454 & \\
\hline C. suaveolens & San Nicolo, IT & IZEA 7509 & IT2 & 48 & AY843453 & A5 \\
\hline C. suaveolens & Gordevio, $\mathrm{CH}$ & IZEA 3198 & $\mathrm{CH} 1$ & 49 & AY843452 & A5 \\
\hline
\end{tabular}




\section{ARTICLE IN PRESS}

Table 1 (continued)

\begin{tabular}{|c|c|c|c|c|c|c|}
\hline Species & Sample location & Collection codes & $\begin{array}{l}\text { Identification } \\
\text { codes }\end{array}$ & $\begin{array}{l}\text { Number on } \\
\text { the map }\end{array}$ & $\begin{array}{l}\text { Accession number } \\
(c y t-b)\end{array}$ & $\begin{array}{l}\text { BRCA1 } \\
\text { allele(s) }\end{array}$ \\
\hline C. suaveolens & Thessaloniki, GR & IZEA 1352 & GR4 & 50 & AY843449 & \\
\hline C. suaveolens & Fülophasa, HU & IZEA 6732 & HU2 & 51 & AY843451 & A6 \\
\hline C. suaveolens & Astrakhanskaya reg., RU & ZISP T-72688 & RU11 & 52 & AY843477 & A1 \\
\hline C. suaveolens & Stavropol, RU & IZEA 4200 & RU12 & 53 & AY843467 & A1 \\
\hline C. suaveolens & Sevastopol, UA & IZEA $7796^{*}$ & UA1 & 54 & AY843475 & A1 \\
\hline C. suaveolens & Krasnodarsskyi, RU & ZISP T-73479 & RU13 & 55 & AY843476 & \\
\hline C. suaveolens & Kazan, RU & ZISP T-85944 & RU14 & 56 & AY843483 & A1 \\
\hline C. suaveolens & Wien, AU & GenBank & AU1 & 57 & AB077280 & \\
\hline C. suaveolens & Fraitusa, IT & IZEA 7977 & IT3 & 59 & AY843494 & \\
\hline C. suaveolens & Fraitusa, IT & IZEA 7979 & IT4 & 59 & AY843493 & A9 \\
\hline C. suaveolens & Ventimiglia, IT & IZEA 7944 & IT5 & 60 & AY 843495 & \\
\hline C. suaveolens & Sandanski, BG & IZEA 7975 & BG1 & 61 & AY843458 & A4 \\
\hline C. suaveolens & Vercelli, IT & IZEA 7945 & IT6 & 62 & AY843459 & \\
\hline C. suaveolens & Latisana, IT & IZEA 7978 & IT7 & 63 & AY843457 & \\
\hline C. suaveolens & Latisana, IT & IZEA 7976 & IT8 & 63 & AY843456 & A5 \\
\hline C. nigripes & Sulavesi, ID & IZEA 4400 & ID1 & - & DQ059024 & ID1 \\
\hline C. brunnea & Java, ID & IZEA 4549 & ID2 & - & DQ059025 & ID2 \\
\hline
\end{tabular}

Abbreviations of countries are: Austria (AU), Azerbaijan (AZ), Bulgaria (BG), Japan (JP), China (CN), England (GB), France (FR), Georgia (GE), Greece (GR), Hungary (HU), Indonesia (ID), Iran (IR), Italy (IT), Mongolia (MN), Russia (RU), South Korea (KR), Spain (ES), Switzerland (CH), Tajikistan (TJ), Turkmenistan (TM), Turkey (TR), and Ukraine (UA). Main collections are mentioned in the text; sequences taken from GenBank are mentioned under collection codes.

Table 2

Primers designed in our laboratory, location on mitochondrial genome for the $c y t-b$ primers, and on the whole amplified fragment for BRCA1 primers

\begin{tabular}{|c|c|c|}
\hline Primer (abbreviation) & Primer sequence & Location \\
\hline Cytb1 (C1) & $5^{\prime}$-tta ttc gca gta ata gca aca gc-3' & $15138-15160$ \\
\hline Cytb2 (C2) & $5^{\prime}$-ata tgg ggtggt gtg ttg agg- $3^{\prime}$ & $15563-15583$ \\
\hline Cytb3 (C3) & $5^{\prime}$-tat tct cec cag aca tat tag g- $3^{\prime}$ & $15511-15532$ \\
\hline Cytb4 (C4) & $\begin{array}{l}5^{\prime} \text {-aac tgt tgc tcc tca gaa tga tat } \\
\text { ttg acc tca- } 3^{\prime}\end{array}$ & $15183-15216$ \\
\hline Cytb5 (C5) & $5^{\prime}$-tat ttt ccc cag ata tgt tag g- $3^{\prime}$ & $15511-15532$ \\
\hline Cytb6 (C6) & $5^{\prime}$-ctt gaa aca tga aac att gg-3' & $15108-15127$ \\
\hline Cytb7 (C7) & $5^{\prime}$-aat aga aaa tat cat tct gg- $3^{\prime}$ & $15588-15607$ \\
\hline BRCAlf (Bf) & $5^{\prime}$-tga gaa cag cac ttt att act cac-3' & $0-24$ \\
\hline BRCA1r (Br) & $5^{\prime}$-att cta gtt cca tat tgc tta tac tg- $3^{\prime}$ & $913-938$ \\
\hline BRCA1f2 (Bf2) & $5^{\prime}$-aag tag aag agt cet ctc c- $3^{\prime}$ & $472-490$ \\
\hline BRCA1r2 (Br2) & $5^{\prime}$-gca gtt caa gtt agg gaa gc-3' & $552-571$ \\
\hline BRCA1f3 (Bf3) & $5^{\prime}-\operatorname{tga}$ ttg gtt ttc tag aag tg- $3^{\prime}$ & $295-314$ \\
\hline BRCA1r3 (Br3) & $5^{\prime}$-atc atg gaa atc atc aga ag-3' & $327-346$ \\
\hline BRCA1f4 (Bf4) & $5^{\prime}$-ctt gaa ctg cac aac tga ag-3' & $562-581$ \\
\hline BRCA1r4 (Br4) & $5^{\prime}-\operatorname{ttg}$ tga agg ggt gtt tgt gt- $3^{\prime}$ & $622-641$ \\
\hline BRCA1dr (Bdr) & $5^{\prime}$-ctc gat ttt ctt ttc agg aga- $3^{\prime}$ & $728-748$ \\
\hline BRCAlfa (Bfa) & $5^{\prime}$-gta ata aaa gta aac agt ctg gc-3' & $60-82$ \\
\hline BRCA1f11 (Bf11) & $5^{\prime}$-aga gca aaa ggc aga tct g- $3^{\prime}$ & $154-172$ \\
\hline BRCA1r11 (Br11) & $5^{\prime}$-ggt ttt ctt ctt cca tat agg- $3^{\prime}$ & $184-204$ \\
\hline BRCA1f12 (Bf12) & $5^{\prime}$-atg act tgg atg act tcg ac- $3^{\prime}$ & $254-273$ \\
\hline BRCA1r12 (Br12) & $5^{\prime}$-cca atc att aac ttt ctg c- $3^{\prime}$ & $283-301$ \\
\hline BRCA1f13 (Bf13) & $5^{\prime}$-gca ggg tct aat tca aat ac $3^{\prime}$ & $347-366$ \\
\hline BRCA1r13 (Br13) & $5^{\prime}$-gct gca ctt ggg att tct tc $3^{\prime}$ & $380-399$ \\
\hline BRCA1f14 (Bf14) & $5^{\prime}$-cca gtg atc agt gtg atg c $3^{\prime}$ & $441-459$ \\
\hline BRCA1r14 (Br14) & $5^{\prime}$-gtt tgg aga gga ctc ttc tac $3^{\prime}$ & $474-494$ \\
\hline BRCA1f15 (Bf15) & $5^{\prime}$-gag gaa agc aag ctt ccc ta $3^{\prime}$ & $541-560$ \\
\hline BRCA1r15 (Br15) & $5^{\prime}-\mathrm{g}$ tta cat ctt cag ttg tgc $3^{\prime}$ & $570-587$ \\
\hline BRCA1f16 (Bf16) & $5^{\prime}$-cac cec ttc aca aat aaa tta $3^{\prime}$ & $629-649$ \\
\hline BRCA1r16 (Br16) & $5^{\prime}$-ct cag gac caa ggc ttg atg $3^{\prime}$ & $669-688$ \\
\hline BRCA1f17 (Bf17) & $5^{\prime}$-gat tgt tca aaa gtc tcc tg $3^{\prime}$ & $715-734$ \\
\hline BRCA1r17 (Br17) & $5^{\prime}$-cat ttt gat cca ttt ggt tg-3' & $754-773$ \\
\hline BRCA1r18 (Br18) & $5^{\prime}$-ga tga tgc tgt tga gtt agc--3' & $848-867$ \\
\hline
\end{tabular}

\subsection{Molecular clock}

Estimation of divergence time from the molecular data was performed, according to the calibration developed for the Soricidae by Fumagalli et al. (1999), based on an estimate of 20 million years for the split between Crocidurinae and Soricinae. It was developed considering the $c y t-b$ sequence divergence based on third-position transversions. As proposed by Edwards (1997), the genetic distance between two different populations was corrected for ancestral mtDNA polymorphism using the formula: $P_{\text {net }}=P_{\mathrm{AB}}-1 / 2\left(P_{\mathrm{A}}+P_{\mathrm{B}}\right)$, where $P_{\text {net }}$ is the corrected distance between the isolated populations $\mathrm{A}$ and $\mathrm{B}, P_{\mathrm{AB}}$ is the mean genetic distances in pairwise comparisons of individuals from A vs. B, and $P_{\mathrm{A}}$ and $P_{\mathrm{B}}$ are the mean genetic distance among individuals within these populations.

To identify whether there was heterogeneity in the rates of $c y t$-b substitutions among different clades, relative-rate tests were conducted between each of them. The relative rate tests were performed with RRTREE, version 1.0 (Robinson et al., 1998), which improves the test of $\mathrm{Wu}$ and $\mathrm{Li}(1985)$ by taking into account taxonomic sampling and phylogenetic relationships. Relative-rate tests were performed on the proportions of synonymous $\left(K_{\mathrm{s}}\right)$, non-synonymous $\left(K_{\mathrm{a}}\right)$ substitutions, and synonymous transversions (B4).

\subsection{Nucleotide diversity and genetic structure}

Nucleotide diversity $(\pi)$ was estimated using the DnaSP program version 4.10.3 (Rozas et al., 2005). The population genetic structure was determined by an analysis of molecular variance (AMOVA), available in Arlequin version 2.0 (Schneider, 2000). This analysis was performed at two 
different hierarchical levels: among clades and within clades.

\subsection{Expansion time}

To test the hypothesis of recent population growth from low-diversity founder populations within the different clades, several tests were performed. Three methods were implemented in DnaSP program version 4.10.3 (Rozas et al., 2005) and one in Arlequin version 2.0 (Schneider, 2000). The first method, Ramos-Onsins and Rozas (2002) $R_{2}$ statistic, is based on the difference between the number of singleton mutations and the average number of nucleotide differences. Lower values of $R_{2}$ are expected under a scenario of recent population growth. The second method, Fu's (1997) $F_{\mathrm{S}}$ statistic, tests the probability of having no fewer than the number of observed alleles in the sample given that $\theta$ (heterozygosity per sites $)=\pi$. This statistic tends to be negative when there is an excess of recent mutations (or rare alleles). The third method, Tajima's (1989) $D$ statistic, tests the null hypothesis that two estimates of the neutral mutation parameter, one derived from the average number of pairwise nucleotide differences and the other based on the number of segregating sites in the sample, are equal. In the fourth test, pairwise mismatch distributions among individuals were plotted and tested for goodness-of-fit to a model of sudden expansion using parametric bootstrapping with 1000 replicates (Schneider and Excoffier, 1999). Expansion time after the bottleneck was estimated from the mismatch distribution $(\tau)$ (Rogers, 1995) and uncorrected $(p)$ distances. Evolutionary rate for uncorrected $(p)$ distance was estimated using the molecular clock developed by Fumagalli et al. (1999).

\section{Results}

\subsection{Cytochrome b gene}

The 76 sequences of $998 \mathrm{bp}$ used in this study showed 315 variable sites, of which 246 were parsimony-informative. No insertions or deletions were observed. As the three phylogenetic methods gave identical arrangements of the main branches, the relationship between haplotypes is given only for the ML analysis in Fig. 2.

Seven major clades strongly supported by bootstrap values (all of $100 \%$ ) were observed:

Clade I: is the most basal, and comprises all haplotypes from Eastern Asia, corresponding to the morphotype C. shantungensis.

Clade II: includes all haplotypes from Russia and central Asia, which correspond to two different morphotypes C. suaveolens, including a specimen of the type locality in the Ukraine, and C. sibirica (Fig. 4).

Clade III: includes two specimens of $C$. caspica and one specimen of $C$. gueldenstaedtii from Georgia. This clade is closely related with clade II (central Asia and Russia), with which they formed a well-distinct group (bootstrap value $>88 \%$ ).

Clade IV: comprises haplotypes of the morphotype C. suaveolens from West Europe (France, Spain, England, and Liguria in Italy). It is the most basal clade of European $C$. suaveolens. It includes several sub-species, e.g., C. suaveolens cantabra Cabrera, 1908; described from Spain.

Clade V: includes all haplotypes of the morphotype $C$. monacha from north and east Turkey, the haplotype of $C$. suaveolens from Corsica and, with one exception, all haplotypes of the morphotype $C$. gueldenstaedtii from Georgia. Thus, it is not possible to dissociate $C$. gueldenstaedtii from $C$. monacha. This clade and the two remaining formed a highly supported clade (bootstrap values $>97 \%$ ).

Clade VI: includes the haplotypes of the morphotype C. suaveolens from Lesvos (Greece) and west Turkey, which has been considered as the nominal sub-species (Corbet, 1978).

Clade VII: comprises all haplotypes of the morphotype C. suaveolens from South and Central Europe (Greece, Italy, Switzerland, Austria, Bulgaria, and Hungary). It includes several sub-species, such as C. $s$. mimula Miller, 1901; from Switzerland, C. s. balcanica Ondrias, 1970; from Greece, and C. s. italica Cavazza, 1912; from Italy.

The AMOVA shows that the majority of the total mtDNA variation $(89.71 \%)$ is distributed among the seven clades, whereas a low percentage of this variation $(10.29 \%)$ is observed within clades. Mean pairwise corrected K2P distances between clades (Edwards, 1997) range from 3.7 to 10.8\% (Table 3).

Within clades, K2P distances are less than $2.5 \%$, and nucleotide diversities range from 0.004 to 0.012 (Table 3). In spite of having by far the largest sample size, nucleotide diversity in clade II was similar or even smaller than those found in the other clades.

\subsection{Molecular clock}

The calibration developed by Fumagalli et al. (1999) for the Soricidae helped to estimate the divergence times between the main lineages within the C. suaveolens group, although it could not be used directly because of the low numbers of third-position transversions observed. Therefore, we estimated the correlation between the third position transversions and maximum likelihood distances (ML distances) inferred from a ML tree constrained to clock-like evolution after adding published sequences of the main lineages of Crocidura species in Europe (Vogel et al., 2003). No evidence of saturation was detected between the main lineages observed within the Crocidura species in Europe, suggesting that all substitutions may be included in such analyses without degradation of the phylogenetic signal. 


\section{ARTICLE IN PRESS}

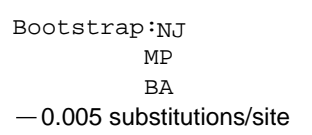

C. shantungensis RU2, RU5 - C. shantungensis KR1 -C. shantungensis RU3 C. Shantungensis RU3 C. Shantungensis KR5 C. shantungensis RU4 C. shantungensis KR2 C. shantungensis KR3 C. shantungensis JP 7

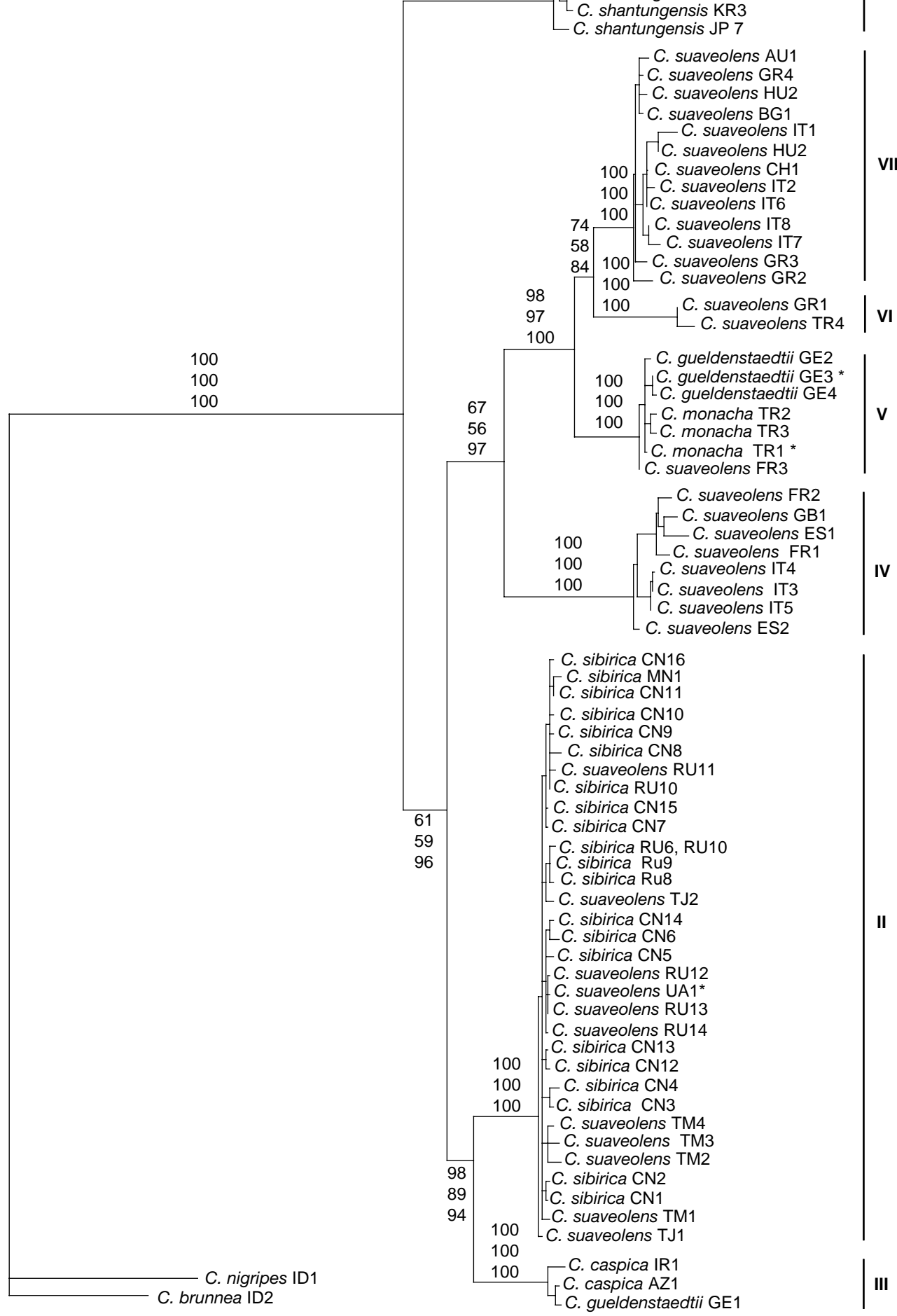

Fig. 2. Phylogeny of the $998 \mathrm{bp} c y t-b$ fragment analysed with maximum likelihood, using the TVM $+\mathrm{G}$ model of substitution and TBR branch swapping. Values in branches are bootstrap indices of support for the major branches for Bayesian (BA), parsimony (MP), and distance (NJ) analyses (percentage of 1000 replications for each of the 10 random orders of stepwise addition of sequences). Codes are as in Table 1.

A good correlation was observed $(r=0.88, P<0.001)$ giving a rate of $0.057 \mathrm{ML}$ distance per million years, with a $95 \%$ confidence interval of $0.044-0.070 \mathrm{ML}$ distance.
Relative-rate tests revealed that clade $\mathrm{V}$ evolved more rapidly than clades VI and VII $(P<0.05)$. Moreover, there were no significant differences in evolutionary rate between 
Table 3

Mean corrected pairwise sequence divergences between the seven clades (Kimura two-parameter distances); diagonally, mean pairwise sequence divergence (K2P) and nucleotide diversity within clades

\begin{tabular}{lllllll}
\hline & I & II & III & IV & V & VI \\
\hline I & $0.009 / 0.009$ & & & & & \\
II & 0.082 & $0.007 / 0.007$ & & & & \\
III & 0.079 & 0.047 & $0.009 / 0.009$ & & & \\
IV & 0.094 & 0.079 & 0.084 & $0.013 / 0.012$ & & \\
V & 0.102 & 0.077 & 0.083 & 0.078 & $0.005 / 0.005$ & $0.005 / 0.006$ \\
VI & 0.108 & 0.083 & 0.083 & 0.079 & 0.054 & 0.037 \\
VII & 0.092 & 0.069 & 0.073 & 0.059 & 0.036 & $0.024 / 0.010$ \\
\hline
\end{tabular}

any other clades $(P>0.05)$. We, thus, decided to exclude clade V from the molecular clock analysis. Dating of the major splits was then estimated using the calibration of Fumagalli et al. (1999). The oldest split corresponds to the separation between eastern Asian haplotypes (morphotype C. shantungensis, clade I) and all the others. This event took place about 1.94 Myr BP [1.58-2.52], i.e., during the Upper Pliocene (Ogg, 2004). The events that separated the European and central Asian clades occurred more recently, around the beginning of the Pleistocene (clades $(\mathrm{IV})+(\mathrm{VI})+(\mathrm{VII})$ vs. (II) + (III), 1.88 Myr BP [1.53-2.42]) Then, later in the Lower Pleistocene, occurred the split between western and eastern European haplotypes (clades (VI) + (VII) vs. (IV), 1.72 Myr BP [1.40-2.23]). The most recent partition was found between clades VI (Italy-Balkans) and VII (west Turkey), with an estimated divergence time situated at the end of the Lower Pleistocene $(0.94 \mathrm{Myr}$ BP [0.76-1.21]). Finally, the split between clades II and III is dated at 1.12 Myr BP [0.91-1.45].

\subsection{Expansion time}

Clade II, comprising Russian and central Asian haplotypes, revealed a signature of population expansion. We observed a non-significant $P$ value for the mismatch distribution test of goodness-of-fit $(P=0.33)$ and a significant $P$ value for $R_{2}, F_{\mathrm{S}}$, and Tajima's $D$ statistics $(P<0.05)$. The timing of this expansion was estimated from the mismatch distribution ( $\tau=7.025$ and $95 \%$ CI: 4.70-8.24), according to Rogers (1995). Assuming no saturation of uncorrected distances $(p)$ (correlation with third position transversions was $r=0.86, P<0.01$ ), distance was 0.0612 per million years (95\% CI: 0.054-0.069). With a generation time of 1 year, the population expansion time was estimated at 58,000 years BP (95\% CI: 34,000-76,000). Concerning the other clades, Tajima's $D$ and $R_{2}$ statistics did not show evidence of population expansion, whereas $F_{\mathrm{S}}$ statistics were significant for clades V and VII. Consequently, we inferred a scenario of non-expansion for the latter.

\subsection{BRCAl gene}

A striking result from our mtDNA analysis is the discrepancy between some morphotype assignments and the clustering pattern of their haplotypes. For example, clade II includes haplotypes from $C$. sibirica and $C$. suaveolens, clade III includes haplotypes from C. caspica and C. gueldenstaedtii, and clade $\mathrm{V}$ includes haplotypes from C. monacha and $C$. gueldenstaedtii morphotypes. This could result either from the invalidity of the species assignments or from the introgression events in some species of the mtDNA from another species, following hybridisation. To resolve this question, we analysed BRCA1, a nuclear gene. This analysis failed for C. gueldenstaedtii sample of clade III, probably due to damaged DNA in this old specimen.

The 15 different sequences of $799 \mathrm{bp}$ showed 44 variable sites, of which 25 are parsimony-informative, and one deletion of three nucleotides (allele A1). In the 10 samples from clade II, three alleles were found (named 1-3; see Table 1) and four heterozygotes detected. Since the four heterozygotes possessed one copy of an allele showing the deletion, we designed a primer on this region of the gene (BRCA1dr) to amplify the other alleles only and to attribute the bases correctly at the polymorphic sites. On the other hand, no heterozygote was detected in the other clades and no polymorphism within clades I, III, and V. In the five analysed samples of clade VII, three different alleles were found (named 4-6). Two alleles were found within clades IV (named 9 and 10) and VI (named 7 and 8). Accession numbers are as follows: alleles A1-A6, AY839147-AY839152; alleles A7-A13, DQ059014-DQ059020. The phylogenetic signal from the BRCA1 gene does not contradict that of $c y t-b$ (Fig. 3). But, the relationships between clades are partially unresolved. Samples of clade II, morphotypes C. sibirica and $C$. suaveolens from Russia and Ukraine, cluster together and differ from clade VII (morphotype C. suaveolens from Switzerland, Italy, Greece, Hungary, and Bulgaria). C. monacha and C. gueldenstaedtii from clade $\mathrm{V}$ share the same allele, as well as the two $C$. caspica. In contrast to $c y t-b$, clade V is closer to clades II and III than those of central Europe, and western Turkey (clades VI and VII), but it is weakly supported by bootstrap values ( $61 \%$ in $\mathrm{MP}$, and $63 \%$ in ML).

\section{Discussion}

\subsection{Genetics versus morphology}

From our results, $C$. sibirica, although morphologically distinct (Zaitsev, 1993), cannot be confirmed as a valid 


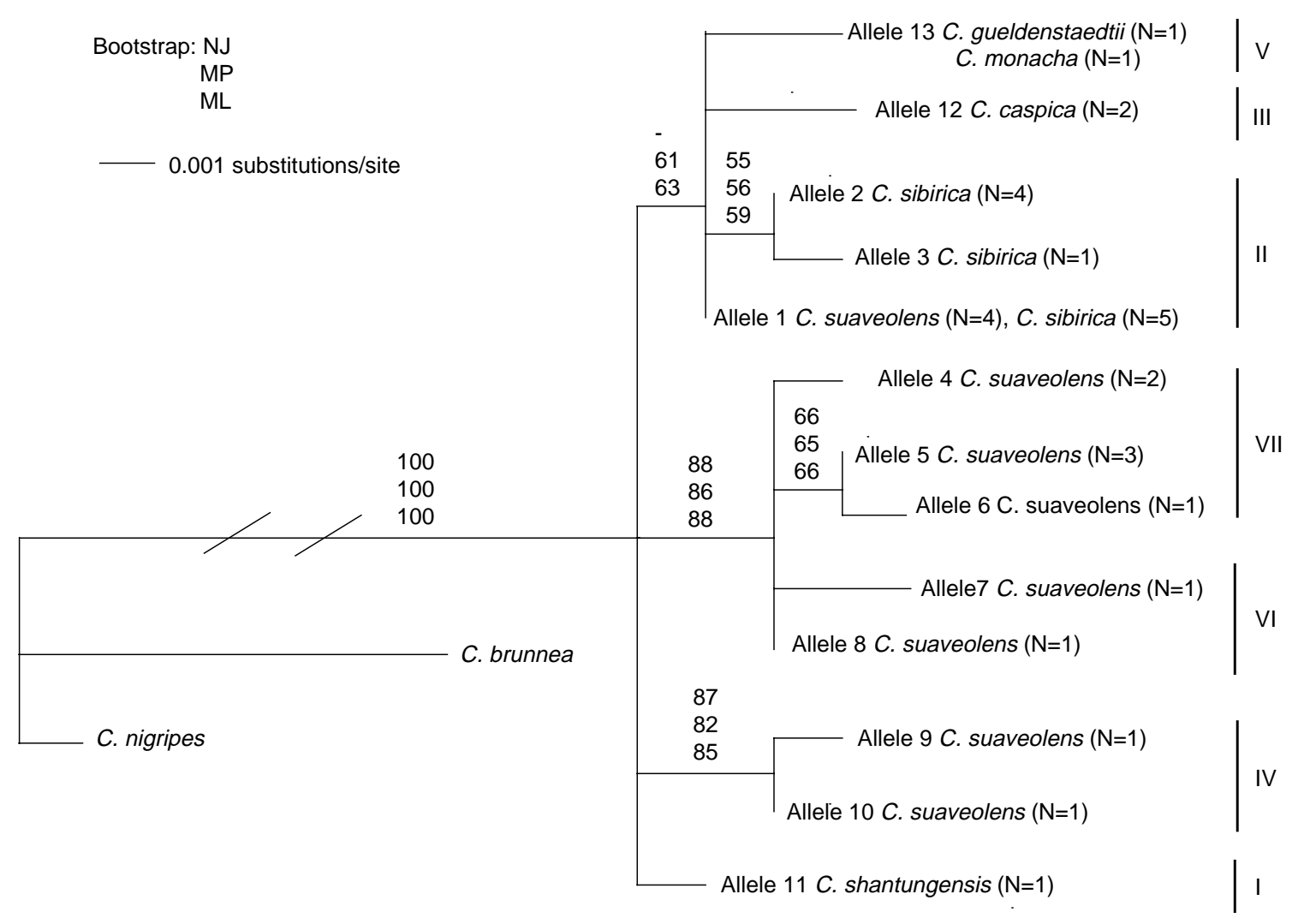

Fig. 3. Phylogeny of the 799 bp BRCA1 fragment analysed with maximum likelihood, using K81 uf model of substitution and TBR branch swapping. Values in branches are bootstrap indices of support for distance (NJ), maximum parsimony (MP), and maximum likelihood (ML) analyses (percentage of 1000 replications for each of the 10 random orders of stepwise addition of sequences). Alleles 1-3 belong to clade II, 4-6 to clade VII, 7 and 8 to clade VI, 9 and 10 to clade IV, 11 to clade I, 12 to clade III, and 13 to clade V.

species. Indeed, this taxon is genetically inseparable from C. suaveolens from the type locality (near Sevastopol, Ukraine), belonging to the same clade (II). A possible introgression of the mitochondrial genome can be rejected, because nuclear and mitochondrial genes gave the same results. It is interesting to note that Bannikova et al. (1993, 2005), using Short Interspersed Nuclear Elements (SINEs), did not find the same results. In fact, $C$. suaveolens from western Russia (Dagestan, Moscow, and Kalmykia) form a well-defined clade, which is distinct of $C$. sibirica from Siberia (Kemerovo). With regards to our results, we suspect that all their samples do belong to clade II. Thus, the tree based on their non-coding sequences represents an internal structure inside clade II. It would, nevertheless, be interesting to screen our samples with the same SINE markers to clarify the situation.

Concerning $C$. caspica, both nuclear and mitochondrial genes point it as an evolutionarily independent unit within the suaveolens complex, although its taxonomic rank as species or subspecies requires further research. We were not able to amplify the nuclear gene of a sample with a C. gueldenstaedtii morphotype and a mtDNA similar to C. caspica. Consequently, a possible introgression of the mitochondrial genome of $C$. caspica into $C$. gueldenstaedtii cannot be rejected. The analysis of BRCA1 and $c y t-b$ genes of numerous samples from both morphotypes, particularly along their contact zone, should be an urgent priority. Moreover, the nuclear results suggest a closer relationship between clade V (C. gueldenstaedtii and C. monacha) and clade III (C. caspica), and II (C. sibirica and C. suaveolens), than the mitochondrial analyses, which could be the result of shared ancestral polymorphism and, or, hybridisation between them.

The age of the C. suaveolens group, its huge distribution area, and the marked phylogeographic structure here detected may imply instances of consummated or ongoing speciation processes. Therefore, the question arises whether the most basal branches have reached the level of biological species. Such species are easily recognised when living in sympatry. However, in the case of a parapatric distribution, the interruption of gene flow in the contact zone is the only diagnostic criterion on which a decision can be based (Brünner et al., 2002), whereas high genetic distances might just suggest scenarios that need more detailed investigations. A study of four genera of rodents and seven genera of bats (Bradley and Baker, 2001) showed a mean intraspecific divergence of $2.1 \%$ (up to $6.3 \%$ ) for rodents and $3 \%$ (up to $8.7 \%$ ) for bats, and a mean divergence between sister species of $8.1 \%(2.5-19.2 \%)$. For rodents, values of $4.7 \%$ between north and southern branches of Arvicola terrestris (Taberlet et al., 1998) and 5.2\% between eastern and western branches of Microtus agrestis (Hellborg et al., 2005) were suspected to 

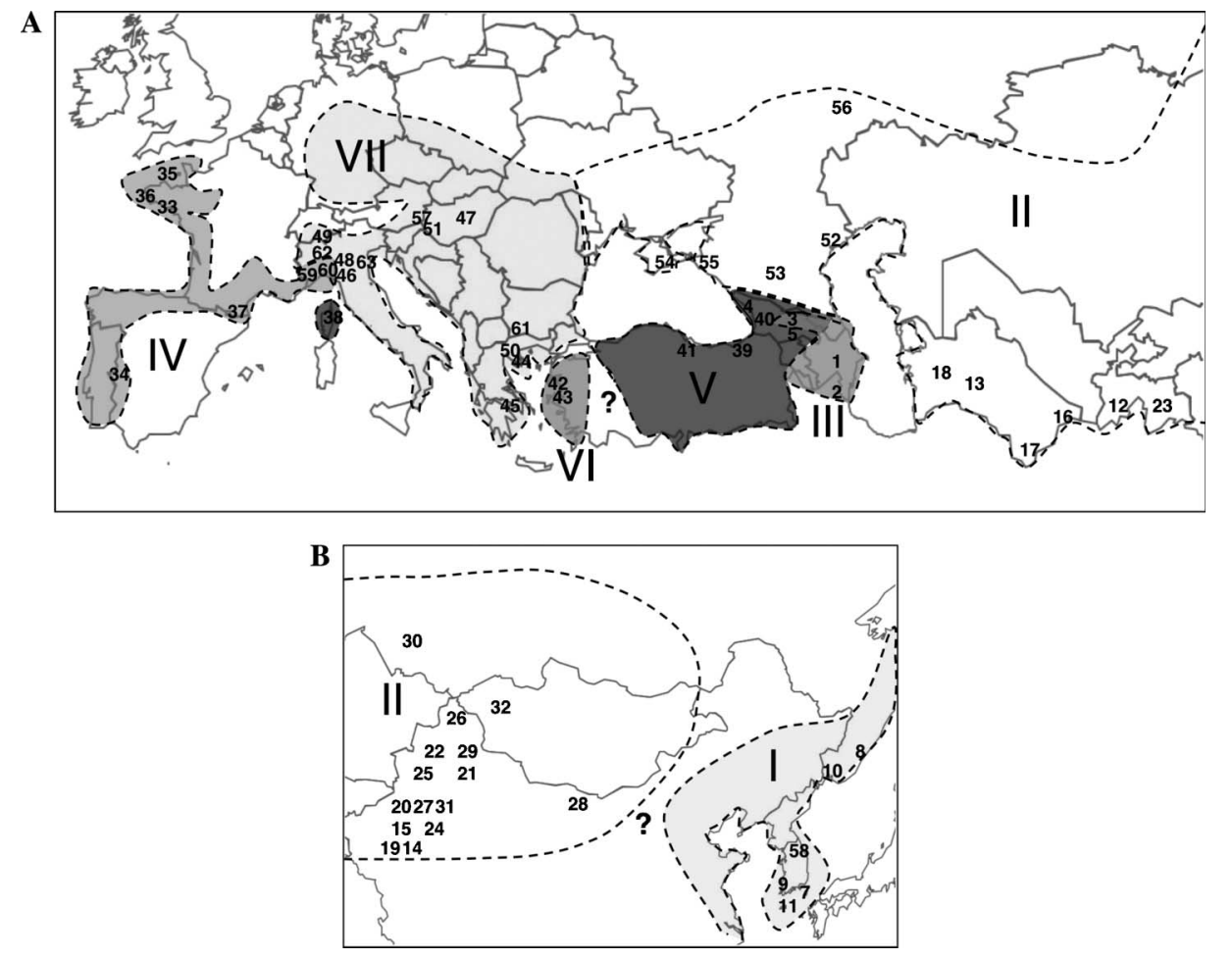

Fig. 4. Repartition of the clades found in our study ((A) II to VII; (B) I, II), with sample locations.

possibly indicate different species. In shrews, eastern and western branches of Crocidura russula, with 9\% divergences (Vogel et al., 2003), showed male sterility of F1 hybrids in captivity (Vogel et al., 2004) and are, therefore, considered to present two species (Brändli et al., in press; Cosson et al., 2005). The contact zone situated in Algeria is not known and, therefore, the disruption of gene flow is not yet proven.

The K2P distance of $4.7-10.8 \%$, as shown for the C. suaveolens group, may be situated within a single species, incipient species or well-separated full species. As morphological taxa (probably strongly conditioned by local selective forces) are not congruent with genetic clades, we consider premature to ascribe distinct species names to the different genetic populations. Their distribution seems to be parapatric and nothing is yet known regarding gene flow at the contact zones. Under these conditions, our interpretation is deliberately conservative. Based on the highest genetic distance between $C$. shantungensis (clade I) and all other clades, we accept the species assignment of this one by previous authors (Jiang and Hoffmann, 2001; Motokawa et al., 2000; Ohdachi et al., 2004). Concerning the other clades (II-VII), we could not exclude the presence of species and, or incipient species. However, the only way to unravel this question is to study gene flow at the contact zones of the respective populations (see Fig. 4).

\subsection{Barriers, refugia, and colonisation routes in Eurasia}

The current distribution of the C. suaveolens group throughout the Palaearctic is roughly limited to the north by the 50th parallel, which corresponds to the transition between the temperate and coniferous forests. This and other considerations, such as altitudinal limits within temperate areas, suggest that the ' $C$. suaveolens' range is limited by cold climates. During the Middle Pliocene, i.e., 3.62.5 Myr BP, the climate was hotter and wetter than today (Chandler et al., 1994; Combourieu-Nebout et al., 2000; Fauquette and Bertini, 2003; Willis et al., 1999). The distributions of deciduous and coniferous forest biomes were shifted to the north by 10 or so latitudinal degrees. The major part of Eurasia was then covered by deciduous forest, which corresponds approximately to the habitat of the C. suaveolens group. Coniferous forests were situated where the tundra and arctic desert are found at present (Haywood et al., 2002; Thompson and Fleming, 1996). Probably, C. suaveolens was then continuously distributed in Eurasia, from the Atlantic to the Pacific coast, more to the north than today.

During the Upper Pliocene (2.5-1.84 Myr BP), the climate became colder and drier (Webb and Bartlein, 1992), leading to a rarefaction of the deciduous forest, with favourable habitats located more to the south $\left(40-50^{\circ}\right.$ latitude), and limited to low altitude, or near the Pacific and the Atlantic Ocean coast. With the first major glaciations at the beginning of the Pleistocene (1.84 Myr BP), we suppose that the white-toothed shrews of the northern part of eastern Asia (Russia, Mongolia, Xinjiang, and Tibet) became extinct, except the population on the Pacific coast (Fig. 5) that survived all future climatic events (clade I, C. shantungensis). During the same event, the population west of the 


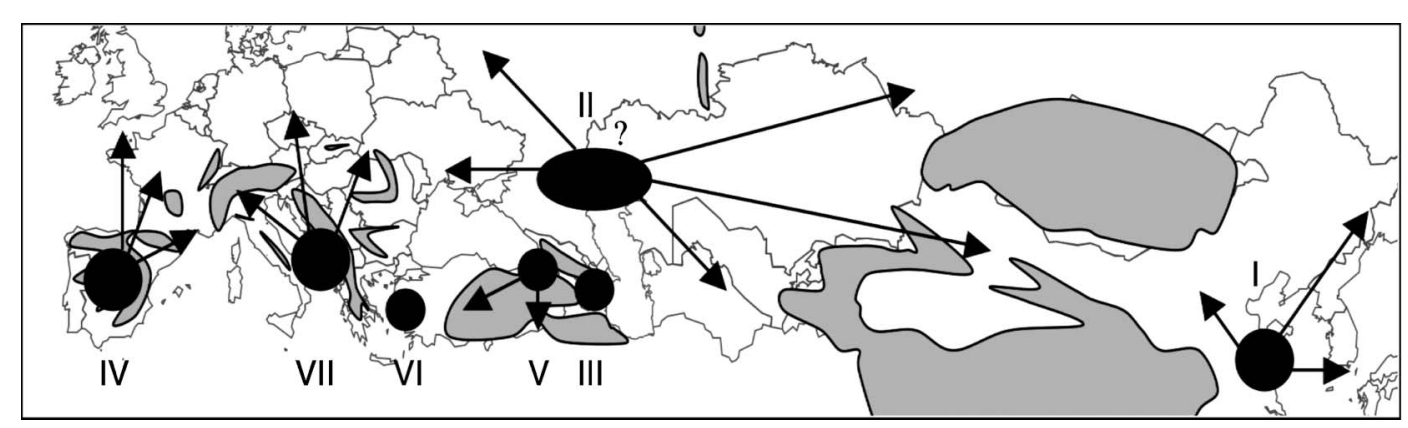

Fig. 5. Potential refuges (black), barriers (grey), and range expansion (arrows) of the seven clades.

Ural Mountains found refugia in southern areas. As southern Eurasia is characterised by some very high plateaus and mountain chains (Himalayas, Pamir, Elburz, Caucasus, and Alps), retracting populations found refugia only in mild lowland habitats, generally situated close to the seashore and isolated from each other by mountain chains. One section (clade II and clade III) probably found refuge east of the Caucasus on the Caspian coast, while the more westerly population (ancestors of clade IV and sister clades) survived in the Mediterranean basin. This split is consistent with the still high divergence between these clades (K2P distance: $6.9-8.4 \%$ ) and might be situated at $1.9 \mathrm{Myr} \mathrm{BP}$ in the Lower Pleistocene.

After a re-colonisation of more northern latitudes, other contractions occurred during less dramatic cold periods allowing survival in different refugia (Fig. 5). Clade II and clade III probably evolved in mild northwestern regions (Black Sea, e.g., Crimea) and southeast of the Caucasus (southern coast of Caspian Sea). These clades are well separated (mean corrected K2P distance: $5.0 \%$ ), similarly to what was observed in the wild goat (Manceau et al., 1999) and in the yellow-necked fieldmouse (Michaux et al., 2004) in the same region. This event is situated in the Lower Pleistocene, 1.1 Myr BP. A refugium northwest of the Caucasus was suggested by Hewitt (1999) for the European oak (Quercus robur-petraea complex) and by Jaarola and Searle (2002) for the field vole (Microtus agrestis), or north of the Caspian Sea, as well as Crimea, as hypothesised by Bilton et al. (1998) for small European mammals showing a recent northern distribution. Clade II is the only one showing evidence of population expansion after a bottleneck, which is supported by a low nucleotide diversity (0.007), despite the large sample size $(n=33)$ and more than $4500 \mathrm{~km}$ separating the more distant samples. This event dates to the Upper Pleistocene, 58,000 years BP (CI: 34,000-78,000), which is approximately situated during a unstable climatic period in Eurasia (Riss-Würm interglacial, 70,000-20,000 years BP), as shown by Dansgaard et al. (1993).

With regard to the western population, clade IV remained in the Iberian Peninsula, colonising France after the last glaciations and coming in contact with clade VII of an Italo-Balkanic refugium at the level where the Alps join the Mediterranean Sea. After the last glaciations, clade VII expanded over a large area of central Europe, including
Germany, Austria, and Hungary. The barrier to the eastern extension is obvious, the Marmara Sea has been, most likely, a barrier to the eastern extension of this clade and restricted clade VI to a western Turkey refugium. The split between clades VI and VII, situated at 938,000 years BP $(764,000-1,216,000)$ corresponds to the Günz glacial period (790,000-950,000 years BP), suggesting a colonisation of western Turkey by animals from central Europe when the sea level was lower. To the south, clade VI was isolated from the clade V by the "Anatolian Diagonal," first described by Davis (1971), a mountain range that extends from northeastern Turkey toward the southwest, dividing Anatolia into two botanical and zoogeographical areas, as found in a phylogeographic work on the horned-nose viper, Vipera ammodytes (Ursenbacher, personal communication).

The refugium of clade $\mathrm{V}$ was possibly situated on the south coast of the Black Sea or again related to the Mediterranean Sea. In fact, according to Catzeflis et al. (1985) shrews from Israel belong to the same phylogeographic clade as shrews from Turkey. A northern extension of this clade during the Holocene was limited to the east by clades II and III, and in the west by clade VI.

\section{Conclusions}

Our investigation was based on a large sample covering a broad range within the distribution of the Crocidura suaveolens group. The results support the monophyly of the Crocidura suaveolens group, which exhibit substantial mitochondrial and nuclear DNA structure across its Eurasiatic range. The seven identified phylogeographical clades are ancient, reflecting isolation during Pliocene climatic fluctuations and Pleistocene glaciations, and likely to have survived in southern refugia during recurrent Ice Ages, as shown in the root vole (Brunhoff et al., 2003; Galbreath and Cook, 2004) and the woodmouse (Michaux et al., 2003). The Western European barriers isolating the populations are those commonly accepted; in contrast, eastern barriers, such as the 'Anatolian Diagonal' and the Caucasus Mountains, are not as well known.

Our results are in agreement with some previous $c y t-b$ gene studies using fewer specimens and restricted to smaller areas in Europe (Vogel et al., 2003) and East Asia 
(Han et al., 2002; Motokawa et al., 2000; Ohdachi et al., 2004). Our sampling, being more thorough, allow for the first time a fairly complete description of the phylogeographic structure of $C$. suaveolens in Eurasia, and suggest that the validity of many taxa in the $C$. suaveolens group has to be re-evaluated. On a more general level, this investigation produced a comprehensive portrait of Pliocene and Pleistocene refugia within the region.

\section{Acknowledgments}

Our highly esteemed co-author Mikhail Zaitsev died on March 17th 2005. For this reason, we express our deep thanks for his collaboration on the systematics of shrews that began many years ago and was cut short much too early. We will never forget him. We are grateful to the following colleagues for tissue samples: A.A. Bannikova, A. Buhnikashvili, F. Catzeflis, F.N. Golenishchev, A.S. Grafodatsky, J. Hausser, T. Maddalena, V.S. Malikov, R. Parapanov, A.A. Stekolshchikov, M. and A. Stubbe, K. Tsuchiya, and E.I. Zholnerovskaya. We thank A.F. Alimov (Russian Academy of Sciences) and L. Keller for the scientific collaboration between Russia and Switzerland, A. Arillo for collaboration with the University of Genova (Italy) and S. Yudong, Chinese Academy of Sciences (Urumqi, Xinjiang, China), for his invitation to P. Vogel. We acknowledge U. Breitenmoser for his help in fieldwork in China, Nelly Di Marco for laboratory facilities, Harvey Woodbridge and Lori-Jayne Lawson Handley for scientific and linguistic advice. This work was supported by the Russian Fund of Basic Research (Grant No. 04-04-49116a), and the Herbette Foundation, University of Lausanne.

\section{References}

Arntzen, J.W., Wallis, G.P., 1991. Restricted gene flow in a moving hybrid zone of the newts Triturus cristatus and Triturus marmoratus in Western France. Evolution 45, 805-826.

Atallah, S.I., 1977. Mammals of the Eastern Mediterranean Region: their ecology, systematics and zoogeographical relationships. Säugetierkd. Mitt. 25, 241-320.

Bannikova, A.A., Lavrenchenko, L.A., Kramerov, D.A., 1993. Molecular phylogeny of the Paleartic white-toothed shrew (pp. 35-39) In: Averianov A., Abramson N. (Eds.), Systematics, Phylogeny and Paleontology of Small Mammals. Russian Academy of Sciences, St. Petersburg, 246 p.

Bannikova, A.A., Lavrenchenko, L.A., Kramerov, D.A., 2005. Phylogenetic relationships between Afrotropical and Palaearctic Crocidura species inferred from Inter-SINE-PCR. Biochem. Syst. Ecol. 33, 45-59.

Bilton, D.T., Mirol, P.M., Mascheretti, S., et al., 1998. Mediterranean Europe as an area of endemism for small mammals rather than a source for northwards postglacial colonization. Proc. R. Soc. Lond. Ser. B Biol. Sci. 265, 1219-1226.

Bradley, R.D., Baker, R.J., 2001. A test of the genetic species concept: cytochrome- $b$ sequences and mammals. J. Mammal. 82, 960-973.

Brändli, L., Handley, L.-J.L., Vogel, P., Perrin, N., in press. Evolutionary history of the greater white-toothed shrew (Crocidura russula) inferred from analysis of mtDNA, Y, and X chromosome markers. Mol. Phylogenet. Evol., doi:10.1016/j.ympev.2005.06.019.

Brunhoff, C., Galbreath, K.E., Fedorov, V.B., Cook, J.A., Jaarola, M., 2003. Holarctic phylogeography of the root vole (Microtus oeconomus): implications for late Quaternary biogeography of high latitudes. Mol. Ecol. 12, 957-968.

Brünner, H., Lugon-Moulin, N., Hausser, J., 2002. Alps, genes, and chromosomes: their role in the formation of species in the Sorex araneus group (Mammalia, Insectivora), as inferred from two hybrid zones. Cytogenet. Genome Res. 96, 85-96.

Catzeflis, F., Maddalena, T., Hellwing, S., Vogel, P., 1985. Unexpected findings on the taxonomic status of East Mediterranean Crocidura russula Auct (Mammalia, Insectivora). Z. Saugetierkd.-Int. J. Mamm. Biol. 50, 185-201.

Chandler, M., Rind, D., Thompson, R., 1994. Joint investigations of the Middle Pliocene Climate. 2. Giss Gcm Northern-Hemisphere Results. Glob. Planet. Change 9, 197-219.

Combourieu-Nebout, N., Fauquette, S., Quezel, P., 2000. What was the late Pliocene Mediterranean climate like: a preliminary quantification from vegetation. Bull. Soc. Geol. Fr. 171, 271-277.

Cooper, S.J.B., Ibrahim, K.M., Hewitt, G.M.., 1995. Postglacial expansion and genome subdivision in the European Grasshopper Chorthippus parallelus. Mol. Ecol. 4, 49-60.

Corbet, G.B., 1978. The Mammals of the Palaearctic Region: A Taxonomic Review. Cornwell University Press, British Museum (Natural History). 314 p.

Cosson, J.F., Hutterer, R., Libois, R., Sara, M., Taberlet, P., Vogel, P., 2005. Phylogeographical footprints of the Strait of Gibraltar and Quaternary climatic fluctuations in the western Mediterranean: a case study with the greater white-toothed shrew, Crocidura russula (Mammalia: Soricidae). Mol. Ecol. 14, 1151-1162.

Dansgaard, W., Johnsen, S.J., Clausen, H.B., et al., 1993. Evidence for general instability of past climate from a $250-\mathrm{Kyr}$ ice-core record. Nature 364, 218-220.

Davis, P.H., 1971. Distribution patterns in Anatolia with particular reference to endemism. In: Davis, P.H., Harper, P.C., Hedge, I.C. (Eds.), Plant Life of South-West Asia. Royal Botanic Garden, Edinburgh, pp. 15-27.

Dumolin-Lapegue, S., Demesure, B., Fineschi, S., LeCorre, V., Petit, R.J., 1997. Phylogeographic structure of white oaks throughout the European continent. Genetics 146, 1475-1487.

Edwards, S.V., 1997. Relevance of microevolutionary processes to higher level molecular systematics. In: Mindell, D.P. (Ed.), Avian Molecular Evolution and Systematics. Academic Press, New York, pp. 251-278.

Fauquette, S., Bertini, A., 2003. Quantification of the northern Italy Pliocene climate for pollen data: evidence for a very peculiar climate pattern. Boreas 32, 361-369.

Ferris, C., Oliver, R.P., Davy, A.J., Hewitt, G.M., 1993. Native oak chloroplasts reveal an ancient divide across Europe. Mol. Ecol. 2, 337-344.

Ferris, C., King, R.A., Vainola, R., Hewitt, G.M., 1998. Chloroplast DNA recognizes three refugial sources of European oaks and suggests independent eastern and western immigrations to Finland. Heredity 80, 584-593.

Fu, Y.X., 1997. Statistical tests of neutrality of mutations against population growth, hitchhiking and background selection. Genetics 147, 915925.

Fumagalli, L., Taberlet, P., Stewart, D.T., et al., 1999. Molecular phylogeny and evolution of Sorex shrews (Soricidae: Insectivora) inferred from mitochondrial DNA sequence data. Mol. Phylogenet. Evol. 11, 222 235.

Galbreath, K.E., Cook, J.A., 2004. Genetic consequences of Pleistocene glaciations for the tundra vole (Microtus oeconomus) in Beringia. Mol. Ecol. 13, 135-148.

Grafodatsky, A.S., Radzhabli, S.I., Sharshov, A.V., Zaitsev, M.V., 1988. Karyotypes of five Crocidura species of the USSR fauna. Tsytologya $30,1247-1250$.

Han, S.H., Iwasa, M.A., Ohdachi, S.D., et al., 2002. Molecular phylogeny of Crocidura shrews in northeastern Asia: a special reference to specimens on Cheju Island, South Korea. Acta Theriol. 47, 369-379.

Haywood, A.M., Valdes, P.J., Francis, J.E., Sellwood, B.W., 2002. Global middle Pliocene biome reconstruction: A data/model synthesis. Geochem. Geophys. Geosyst. 3, 1072. 
Hellborg, L., Gunduz, I., Jaarola, M., 2005. Analysis of sex-linked sequences supports a new mammal species in Europe. Mol. Ecol. 14, 2025-2031.

Hewitt, G.M., 1996. Some genetic consequences of ice ages, and their role in divergence and speciation. Biol. J. Linn. Soc. 58, 247-276.

Hewitt, G.M., 1999. Post-glacial re-colonization of European biota. Biol. J. Linn. Soc. 68, 87-112.

Hewitt, G.M., 2000. The genetic legacy of the quaternary ice ages. Nature 405, 907-913.

Hewitt, G.M., 2003. Ice ages: their impact on species distributions and evolution. In: Rothschild, L.J., Lister, A.M. (Eds.), Evolution on Planet Earth. Academic Press, New York, pp. 339-361.

Huelsenbeck, J.P., Ronquist, F., Nielsen, R., Bollback, J.P., 2001. Evolution: Bayesian inference of phylogeny and its impact on evolutionary biology. Science 294, 2310-2314.

Hutterer, R., 1981. Der Status von Crocidura ariadne Pieper, 1979 (Mammalia: Soricidae). Bonn. Zool. Beitr. 32, 3-12.

Irwin, D.M., Kocher, T.D., Wilson, A.C., 1991. Evolution of the cytochrome $b$ gene of mammals. J. Mol. Evol. 32, 128-144.

Jaarola, M., Searle, J.B., 2002. Phylogeography of field voles (Microtus agrestis) in Eurasia inferred from mitochondrial DNA sequences. Mol. Ecol. 11, 2613-2621.

Jiang, X.L., Hoffmann, R.S., 2001. A revision of the white-toothed shrews (Crocidura) of Southern China. J. Mammal. 82, 1059-1079.

Kimura, M., 1980. A simple method for estimating evolutionary rate of base substitution through comparative studies of nucleotide sequences. J. Mol. Evol. 16, 111-120.

Manceau, V., Despres, L., Bouvet, J., Taberlet, P., 1999. Systematics of the genus Capra inferred from mitochondrial DNA sequence data. Mol. Phylogenet. Evol. 13, 504-510.

Michaux, J.R., Magnanou, E., Paradis, E., Nieberding, C., Libois, R., 2003. Mitochondrial phylogeography of the Woodmouse (Apodemus sylvaticus) in the Western Palearctic region. Mol. Ecol. 12, 685-697.

Michaux, J.R., Libois, R., Paradis, E., Filippucci, M.G., 2004. Phylogeographic history of the yellow-necked fieldmouse (Apodemus flavicollis) in Europe and in the Near and Middle East. Mol. Phylogenet. Evol. 32, 788-798.

Michaux, J.R., Libois, R., Filippucci, M.G., 2005. So close and so different: comparative phylogeography of two small mammal species, the Yellownecked fieldmouse (Apodemus flavicollis) and the Woodmouse (Apodemus sylvaticus), in the Western Palearctic region. Heredity 94, 52-63.

Motokawa, M., Suzuki, H., Harada, M., et al., 2000. Phylogenetic relationships among East Asian species of Crocidura (Mammalia, Insectivora) inferred from mitochondrial cytochrome $b$ gene sequences. Zool. Sci. 17, 497-504.

Nesbo, C.L., Fossheim, T., Vollestad, L.A., Jakobsen, K.S., 1999. Genetic divergence and phylogeographic relationships among European perch (Perca fluviatilis) populations reflect glacial refugia and postglacial colonization. Mol. Ecol. 8, 1387-1404.

Ogg, J.G., 2004. Status of divisions of the International Geologic Time Scale. Lethaia 37, 183-199.

Ohdachi, S., Dokuchaev, N.E., Hasegawa, M., Masuda, R., 2001. Intraspecific phylogeny and geographical variation of six species of northeastern Asiatic Sorex shrews based on the mitochondrial cytochrome $b$ sequences. Mol. Ecol. 10, 2199-2213.

Ohdachi, S.D., Iwasa, M.A., Nesterenko, V.A., Abe, H., Masuda, R., Haberl, W., 2004. Molecular phylogenetics of Crocidura shrews (Insectivora) in east and central Asia. J. Mammal. 85, 396-403.

Palme, A.E., Vendramin, G.G., 2002. Chloroplast DNA variation, postglacial recolonization and hybridization in hazel, Corylus avellana. Mol. Ecol. 11, 1769-1780.

Parker, S.R., 1997. Sequence Navigator. Multiple sequence alignment software. Methods Mol. Biol. 70, 145-154.

Posada, D., Crandall, K.A., 1998. MODELTEST: testing the model of DNA substitution. Bioinformatics 14, 817-818.

Ramos-Onsins, S.E., Rozas, J., 2002. Statistical properties of new neutrality tests against population growth. Mol. Biol. Evol. 19, 2092-2100.

Robinson, M., Gouy, M., Gautier, C., Mouchiroud, D., 1998. Sensitivity of the relative-rate test to taxonomic sampling. Mol. Biol. Evol. 15, 1091-1098.
Rogers, A.R., 1995. Genetic-evidence for a Pleistocene population explosion. Evolution 49, 608-615.

Rozas, J., Sanchez-DelBarrio, J.C., Messeguer X., Rozas R., 2005. DNA Sequence Polymorphism version 4.10.2. Departament de Genetica, Universitat de Barcelona, Spain, (www document) URL < http:// www.ub.es/dnasp/>

Ruedi, M., Smith, M.F., Patton, J.L., 1997. Phylogenetic evidence of mitochondrial DNA introgression among pocket gophers in New Mexico (family Geomyidae). Mol. Ecol. 6, 453-462.

Santucci, F., Emerson, B.C., Hewitt, G.M., 1998. Mitochondrial DNA phylogeography of European hedgehogs. Mol. Ecol. 7, 1163-1172.

Schneider, I., 2000. Software programs for DNA sequence analysis. Genet. Eng. News 20, 8.

Schneider, S., Excoffier, L., 1999. Estimation of past demographic parameters from the distribution of pairwise differences when the mutation rates vary among sites: application to human mitochondrial DNA. Genetics 152, 1079-1089.

Seddon, J.M., Santucci, F., Reeve, N., Hewitt, G.M., 2002. Caucasus Mountains divide postulated postglacial colonization routes in the white-breasted hedgehog, Erinaceus concolor. J. Evol. Biol. 15, 463-467.

Swofford, D.L., 1998. PAUP*. Phylogenetic Analysis Using Parsimony (* and other Methods). Version 4.0b1. Sinauer Associates, Sunderland, MA.

Taberlet, P., Fumagalli, L., Wust-Saucy, A.G., Cosson, J.F., 1998. Comparative phylogeography and postglacial colonization routes in Europe. Mol. Ecol. 7, 453-464

Tajima, F., 1989. Statistical method for testing the neutral mutation hypothesis by DNA polymorphism. Genetics $123,585-595$.

Tegelstrom, H., 1987. Transfer of mitochondrial-DNA from the Northern Red-Backed Vole (Clethrionomys rutilus) to the Bank Vole (Clethrionomys glareolus). J. Mol. Evol. 24, 218-227.

Tembotova, F.A., 1999. The regularities of variability and the evolution of insectivora (Mammalia) of the Caucasus. PhD thesis (English translation), Nalchic.

Thompson, R.S., Fleming, R.F., 1996. Middle Pliocene vegetation: Reconstructions, paleoclimatic inferences, and boundary conditions for climate modeling. Mar. Micropaleontol. 27, 27-49.

Thorpe, R.S., 1984. Primary and secondary transition zones in speciation and population differentiation - a phylogenetic analysis of range expansion. Evolution 38, 233-243.

Vogel, P., Cosson, J.F., Jurado, L.F.L., 2003. Taxonomic status and origin of the shrews (Soricidae) from the Canary Islands inferred from a mtDNA comparison with the European Crocidura species. Mol. Phylogenet. Evol. 27, 271-282.

Vogel, P., Madallena, T., Sara, M., 2004. Crocidura cossyrensis Contoli, 1989 (Mammalia, Soricidae): karyotype, biochemical genetics and hybridization experiments. Rev. Suisse Zool. 111, 925-934.

Webb, T., Bartlein, P.J., 1992. Global changes during the last 3 million years: climatic controls and biotic responses. Annu. Rev. Ecol. Syst. 23, 141-173.

Willis, K.J., Kleczkowski, A., Crowhurst, S.J., 1999. 124,000-year periodicity in terrestrial vegetation change during the late Pliocene epoch. Nature 397, 685-688.

Wu, C.-I., Li, W.-H., 1985. Evidence for higher rates of nucleotide substitutions in rodents than in man. Proc. Natl. Acad. Sci. USA 82, 1741-1745.

Yasuda, S.P., Vogel, P., Tsuchiya, K., Han, S.H., Lin, L.K., Suzuki, H., in press. Phylogenetic patterning of mtDNA in a widely distributed Eurasian temperate rodent, the harvest mouse Micromys minutus (Muridae, Rodentia), suggests dramatic cycles of range contraction and expansion during mid- to late Pleistocene. Can. J. Zool.

Yudin, B.S., 1989. Insectivorous Mammals of Siberia. Nauka, Novosibirsk. $360 \mathrm{p}$.

Zaitsev, M.V., 1993. Species composition and questions of systematics of white-toothed shrews (Mammalia, Insectivora) of the fauna of USSR. In: Zaitsev, M.V. (Ed.), Questions of Systematics, Faunistics and Paleontology of Small Mammals. Proc. Zool. Inst. USSR Acad. Sci. vol. 243, pp. 3-46. 